\title{
Pelanggaran Prinsip Iktikad Baik Terhadap Negosiasi Treaty on Certain Maritime Arrangements in the Timor Sea (Kesepakatan Maritim Khusus di Laut Timor) oleh Australia*
}

\author{
Tiara Ika Winarni**
}

\begin{abstract}
Abstrak
Pada tahun 2006, Australia dan Timor Leste menyepakati Kesepakatan Maritim Khusus Laut Timor (CMATS) sebagai pengaturan sementara mengenai pengelolaan sumber daya alam di ladang Greater Sunrise. Namun enam tahun kemudian, salah seorang mantan agen Dinas Rahasia Intelijen Australia memberikan informasi kepada pemerintah Timor Leste bahwa Australia telah melakukan penyadapan terhadap diskusi internal pemerintah Timor Leste mengenai negosiasi CMATS pada tahun 2004. Penyadapan di dalam negosiasi CMATS dianggap suatu bentuk pelanggaran terhadap kewajiban untuk melaksanakan prinsip iktikad baik dalam pembentukan perjanjian internasional berdasarkan ketentuan di dalam Konvensi Hukum Laut Perserikatan Bangsa-Bangsa maupun Konvensi Wina 1969 tentang Hukum Perjanjian Internasional. Tujuan penulisan artikel ini adalah untuk menganalisa penyadapan sebagai bentuk pelanggaran terhadap kewajiban untuk melaksanakan prinsip iktikad baik di dalam proses negosiasi CMATS, sehingga kesepakatan tersebut dapat dibatalkan. Penyadapan dapat dilihat sebagai unsur penipuan yang merupakan bentuk kecurangan berdasarkan Pasal 49 Konvensi Wina 1969. Dengan demikian, penyadapan merupakan suatu bentuk kecurangan yang merupakan pelanggaran terhadap kewajiban untuk melaksanakan prinsip iktikad baik dalam negosiasi sebagai tahap pembentukan CMATS. Penetapan batas maritim permanen dapat menjadi solusi bagi kedua negara dalam memperoleh kepastian hukum bagi pengelolaan ladang sumber daya alam serta dapat mengikutsertakan pihak ketiga dalam penyelesaian sengketa.
\end{abstract}

Kata Kunci: CMATS, Greater Sunrise, penyadapan, prinsip iktikad baik, sengketa Laut Timor.

\section{Breach of The Good Faith Principle In Treaty on Certain Maritime Arrangements in the Timor Sea Negotiation By Australia}

\author{
Abstract \\ In 2006, Australia and Timor Leste have agreed on Treaty on Certain Maritime Arrangements
}

PADJADJARAN Jurnal IImu Hukum Volume 2 Nomor 1 Tahun 2015 [ISSN 2460-1543] [e-ISSN 2442-9325]

* Artikel ini dibuat berdasarkan Skripsi dengan judul “Pelanggaran Prinsip Iktikad Baik Terhadap Negosiasi Treaty on Certain Maritime Arrangements in the Timor Sea oleh Australia berdasarkan Hukum Internasional" yang telah dipertahankan dalam ujian sidang Sarjana Hukum pada 10 Desember 2014. Penulis mengucapkan terima kasih kepada Bapak H. Atip Latipulhayat, S.H., LL.M., Ph.D. dan Bapak R.A. Gusman Catur Siswandi, S.H., LL.M., Ph.D. selaku dosen pembimbing Penulis yang telah memberikan bimbingan serta arahan kepada Penulis untuk menyelesaikan Skripsi tersebut, serta kepada Bapak Dr. Idris, S.H., M.A., Ibu Dr. Rika Ratna Permata, S.H., M.H., dan Ibu Dr. Hj. Sinta Dewi, S.H., LL.M. selaku dosen penguji yang telah memberikan koreksi dan saran bagi Skripsi Penulis agar dapat menjadi suatu karya tulis yang dapat bermanfaat bagi perkembangan hukum internasional.

**Alumni Fakultas Hukum Universitas Padjadjaran, Jl. Dipati Ukur No. 35 Bandung, tiarawinarni@gmail.com, S.H. (Universitas Padjadjaran). 
in the Timor Sea (CMATS) as a provisional arrangement in regards to resources management in Greater Sunrise field. However, 6 years later a former agent of Australian Secret Intelligence Service provided some information to the government of Timor Leste that Australia has intercepted the internal discussion of CMATS negotiation in 2004. Espionage in the CMATS negotiation deemed as a form of violation to the obligation of good faith principle according to UN Convention on the Law of the Sea and Vienna Convention on the Law of Treaties 1969 (VCLT). The aim of this article is to analyze interception as a breach to the duty of performing good faith principle in the negotiation process and a basis for the arrangement invalidity. Espionage as a form of deceitful proceedings can be assumed as an element of fraudulent conduct which derives from fraud under Article 49 of VCLT. Establishment of permanent maritime boundaries can be applied as a solution for both countries to achieve legal assurance for disputed resource fields management as well as using the third party as solution to Timor Sea dispute resolution.

Keywords: CMATS, Greater Sunrise, espionage, good faith principle, Timor Sea dispute.

\section{A. Pendahuluan}

Pada 20 Mei 2002 Timor Leste menjadi negara merdeka pertama di abad ke-21 setelah Pemerintahan Transisi Perserikatan Bangsa-Bangsa untuk Timor Timur (UNTAET) mengalihkan fungsi dan wewenang pemerintahan sepenuhnya kepada rakyat Timor Leste. ${ }^{1}$ Sejak saat itu pemerintah Timor Leste mulai menata urusan dalam negeri maupun hubungan luar negerinya, termasuk persoalan mengenai pengelolaan sumber daya alam yang berada di Laut Timor. Bersamaan dengan kemerdekaan yang diperoleh Timor Leste, Australia dan Timor Leste menyepakati Perjanjian Laut Timor (PLT) untuk menggantikan Perjanjian Celah Timor yang telah berakhir. ${ }^{2}$

Berkaitan dengan disepakatinya PLT pada tahun 2002, serta masih belum disepakatinya penetapan batas maritim antara Australia dan Timor Leste, dibentuklah Daerah Pengembangan Minyak Bersama (JDPA) ${ }^{3}$ di bawah administrasi Otoritas Khusus untuk Laut Timor. Sementara itu, wilayah di luar JDPA berada di wilayah sengketa klaim oleh kedua negara. ${ }^{4}$

1 Anders B. Johnsson, "Parlemen Nasional Timor-Leste dan Proses Keuangan: Peranan Legislatif dan Pengawasan", Seminar Parlemen dan Anggaran Nasional: Legislatif dan Fungsi Pengawasan, Dili-Timor Leste, 8-9 Mei 2003.

2 Susan Simpson, "A Timeline of Events Leading up to Timor-Leste's ICJ Claims Againts Australia", 2014, http://viewfromll2.com/2014/01/25/a-timeline-of-events-leading-up-to-timor-lestes-icj-claim-againstaustralia/, diakses 27 Februari 2014.

3 Istilah "Daerah Pengembangan Minyak Bersama" yang digunakan oleh Penulis berdasarkan Laporan La'o Hamutuk Institut Pemantau dan Rekonstruksi Timor Leste, "LNG Sunrise di Timor-Leste: Impian, Kenyataan dan Tantangan".

4 Guteriano Neves (et.al.), “LNG Sunrise di Timor-Leste: Impian, Kenyataan dan Tantangan”, Laporan La'o Hamutuk Institut Pemantau dan Rekonstruksi Timor Leste, 2008, hlm. 11. 
Timor Leste dan Australia kemudian melanjutkan kesepakatan teknis PLT melalui Perjanjian Unitisasi Internasional (IUA) pada tahun 2003 dan Perjanjian atas Kesepakatan Maritim Khusus di Laut Timor (CMATS) pada tahun 2006.

CMATS secara khusus membahas mengenai pengoperasian dan pengelolaan ladang minyak Greater Sunrise, yang terletak di luar wilayah JDPA, oleh Australia dan Timor Leste. Masing-masing negara akan menerima 50\% pendapatan dari ladang minyak Greater Sunrise. ${ }^{5}$ CMATS merupakan pengaturan sementara, begitu juga dengan PLT dan IUA, yang dibentuk berdasarkan ketentuan Pasal 74 dan Pasal 83 Konvensi Hukum Laut Perserikatan Bangsa-Bangsa (KHL). Kedua negara sepakat untuk membagi rata pendapatan dari ladang Greater Sunrise yang juga merupakan pembaharuan dari ketentuan dalam IUA sebelumnya. ${ }^{7}$ CMATS mulai berlaku bagi para pihak setelah dilakukan pertukaran nota di Dili, Timor Leste pada 23 Februari 2007. ${ }^{8} \mathrm{Hal}$ tersebut sebagaimana yang telah diatur di dalam Pasal 13 CMATS, bahwa:

"This Treaty shall enter into force on the day on which the Government of Australia and the Government of the Democratic Republic of Timor-Leste have notified each other, in writing, that their respective requirements for the entry into force of this Treaty have been complied with."

Namun pada tahun 2012, salah seorang mantan agen Dinas Rahasia Intelijen Australia (ASIS), memberikan informasi kepada pemerintah Timor Leste bahwa Australia telah melakukan penyadapan terhadap diskusi internal pemerintah Timor Leste mengenai negosiasi CMATS yang dilakukan dengan dalih bantuan renovasi dan konstruksi dari Australia bagi ruang kerja kabinet dan perdana menteri Timor Leste pada tahun 2004. Pada saat itu, mantan agen tersebut turut serta dengan menyamar sebagai kontraktor di dalam misi penyadapan tersebut. ${ }^{9}$ la bertugas untuk meng-install peralatan penyadapan di ruang kerja yang dimaksud, sehingga Australia dapat memperoleh informasi mengenai diskusi internal pemerintah Timor

5 Ibid., hlm. 12.

6 Treaty Between Australia and the Democratic Republic of Timor-Leste on Certain Maritime Arrangements in the Timor Sea ("CMATS"), 12 Januari 2006, ATS 12, Preambule paragraf 3. ("TAKING INTO ACCOUNT the United Nations Convention on the Law of the Sea done at Montego Bay on 10 December 1982 and, in particular, Articles 74 and 83 which provide that the delimitation of the exclusive economic zone and continental shelf between States with opposite or adjacent coasts shall be effected by agreement on the basis of international law in order to achieve an equitable solution").

7 Parliament of Australia, "Australia-East Timor Certain Maritime Arrangements Treaty", dalam Report 85: Treaties Tabled On 6, 7\& 27 February 2007, 2007, hlm. 40.

8 Department of Foreign Affairs and Trade, "Entry into Force of Greater Sunrise Treaties with East Timor," Alexander Downer, Minister of Foreign Affairs, Australia, media release, 2007, www.foreignminister.gov. au/releases/2007, diakses 13 Juni 2014.

9 Peter Llyod, "Brandis Orders ASIO Raids Related To East Timor Spying Case", 2013, http://www.abc.net.au/ am/content/2013/s3904457.htm, diakses 27 Februari 2014. 
Leste. ${ }^{10}$ Hal itulah yang dinyatakan oleh mantan agen Australia melalui surat sumpah setelah ia mengetahui bahwa Alexander Downer, mantan Menteri Luar Negeri yang menjabat saat penyadapan negosiasi tersebut berlangsung, saat ini berprofesi sebagai penasihat perusahaan Woodside melalui perusahaan lobi-nya, Bespoke Approach. ${ }^{11}$

Berdasarkan informasi dari mantan agen ASIS tersebut, pemerintah Timor Leste kemudian mengirimkan nota diplomatik kepada Perdana Menteri Australia pada saat itu, Julia Gillard, untuk menginformasikan mengenai penyadapan yang dilakukan oleh Australia saat negosiasi CMATS serta Timor Leste meminta Australia untuk dapat melakukan diskusi kembali terhadap perjanjian tersebut. ${ }^{12}$ Namun demikian, karena Australia tidak menghiraukan nota diplomatik tersebut maka Timor Leste kemudian melakukan tindak lanjut dengan mengajukan pembatalan perjanjian atas dasar tidak dilaksanakannya negosiasi CMATS dengan prinsip iktikad baik $^{13}$ kepada Permanent Court of Arbitration (PCA), pada 23 April 2013 berdasarkan ketentuan Pasal 23 ayat (b) Annex B Timor Sea Treaty 2002. ${ }^{14}$

Berdasarkan pemaparan di atas, tulisan ini akan mengkaji mengenai kewajiban untuk melaksanakan prinsip iktikad baik dalam proses negosiasi pada fase pembuatan perjanjian pengembangan bersama dan penyadapan sebagai bentuk kecurangan yang merupakan bentuk pelanggaran terhadap prinsip iktikad baik di dalam pembentukan perjanjian internasional, sehingga dapat mengakibatkan dibatalkannya CMATS. Selain itu, tulisan ini juga akan mengkaji mengenai akibat hukum pembatalan CMATS terhadap kerja sama yang dilakukan oleh kedua pihak.

\section{B. Kewajiban Untuk Melaksanakan Negosiasi Pengembangan Bersama dengan Prinsip Iktikad Baik}

Konsep pengembangan bersama merupakan suatu aplikasi untuk mengadakan persetujuan atau pengaturan sementara mengenai penetapan batas maritim apabila belum dicapai kesepakatan mengenainya di antara negara-negara yang wilayah Zona Ekonomi Eksklusif (ZEE) dan/atau landas kontinennya tumpang tindih atau berhadapan sebagaimana diatur oleh Pasal $74 \mathrm{KHL}$ mengenai penetapan batas ZEE dan Pasal 83 (KHL) mengenai penetapan batas landas kontinen. Kedua pasal tersebut memiliki ketentuan yang identik, berbunyi:

\footnotetext{
10 Susan Simpson, Loc. cit.

11 Peter Lloyd, Loc. cit.

12 Susan Simpson, Loc. cit.

13 Penggunaan istilah "Iktikad Baik" ini sebagai terjemahan dari istilah "Good Faith" yang digunakan Penulis berdasarkan Kamus Besar Bahasa Indonesia, Jakarta: PT Gramedia Pustaka Utama, 2008.

14 Timor Leste v. Australia, Pending Cases, Permanent Court of Arbitration (PCA), 23 April 2013, http://www.pcacpa.org/showpage.asp?pag_id=1403, diakses 27 Februari 2014.
} 
"Pending agreement as provided for in paragraph 1, the States concerned, in a spirit of understanding and cooperation, shall make every effort to enter into provisional arrangements of a practical nature and, during this transitional period, not to jeopardize or hamper the reaching of the final agreement. Such arrangements shall be without prejudice to the final delimitation."

Pasal tersebut mengandung dua elemen, yakni kewajiban untuk mengadakan segala usaha ("make every effort") untuk memutuskan suatu pengaturan sementara yang bersifat praktis, serta larangan untuk membahayakan atau menghambat pencapaian mengenai penetapan batas. Elemen yang pertama bertujuan untuk menyelenggarakan usaha-usaha sementara, sedangkan elemen kedua bertujuan untuk membatasi aktivitas negara-negara yang bersangkutan di wilayah yang disengketakan. ${ }^{15}$ Salah satu bentuk pengaturan sementara tersebut diaplikasikan ke dalam pengembangan bersama. Lagoni, selaku Rapporteur di dalam Komite ZEE Asosiasi Hukum Internasional atau International Law Association (ILA) di dalam artikel dan laporannya pada pertemuan di Warsawa tahun 1988, memberikan definisi pengembangan bersama sebagai:

"Cooperation between states based on an agreement regarding the exploration for and exploitation of certain deposits, fields or accumulations of nonliving resources that either extend across a boundary or lie in an area of overlapping claims."

Sehingga pada prinsipnya, pengembangan bersama dilaksanakan melalui kesepakatan perjanjian pengaturan bersama oleh negara-negara yang bersangkutan. Dengan demikian, pengembangan bersama yang dilakukan oleh negara merupakan suatu bentuk perjanjian internasional. Perjanjian internasional sendiri diartikan di dalam Pasal 1 huruf b Konvensi Wina 1969 tentang Hukum Perjanjian Internasional (Konvensi Wina) sebagai:

"an international agreement concluded between States in written form and governed by international law, whether embodied in a single instrument or in two or more related instruments and whatever particular designation."

Sehingga sebagai perjanjian internasional, pengembangan bersama juga tunduk kepada Konvensi Wina sebagai kodifikasi hukum kebiasaan mengenai perjanjian internasional. ${ }^{17}$ Ketentuan di dalam Konvensi Wina membagi pengaturan serta prosedur dalam perjanjian internasional ke dalam tiga bagian, yakni tentang

\footnotetext{
15 Myron H. Nordquist, United Nations Convention on the Law of the Sea 1982 A Commentary, Volume III, Dordrecht : Martinus Nijhoff Publishers, 1989, hlm. 815, 984.

${ }^{16}$ Hazel Fox (et.al.), Joint Development of Offshore Oil and Gas: A Model Agreement for States for Joint Development with Explanatory Commentary, London: British Institute of International and Comparative Law, 1989, hlm. 43-44.

17 Pranoto Iskandar, Hukum HAM Internasional Sebuah Pengantar Konstektual, Cianjur: IMR Press, 2013, hlm. 209.
} 
pembuatan perjanjian internasional, tentang berlaku dan mengikatnya perjanjian internasional, serta tentang berakhirnya perjanjian internasional. ${ }^{18}$ Dalam tahap pembuatan perjanjian internasional, sebelum perjanjian internasional tertulis dibentuk selalu didahului oleh proses perundingan atau negosiasi. ${ }^{19}$ Sedangkan waktu berlakunya dan mengikatnya suatu perjanjian internasional ditetapkan berdasarkan Pasal 24 ayat (1) Konvensi Wina, yakni tergantung kepada ketentuan dari perjanjian internasional itu sendiri serta kesepakatan negara-negara peserta. Dengan demikian, pembentukan perjanjian pengembangan bersama harus didahului oleh proses negosiasi.

Selain itu, pengembangan bersama sebagai perjanjian internasional juga harus tunduk kepada prinsip-prinsip fundamental yang digunakan dalam menyusun perjanjian internasional. Salah satu prinsip tersebut ialah prinsip iktikad baik. Prinsip iktikad baik di dalam Konvensi Wina salah satunya terdapat pada Pasal 26 mengenai prinsip pacta sunt servanda, yang berbunyi:

"Every treaty in force is binding upon the parties to it and it must be performed by them in good faith."

Pasal tersebut menyatakan bahwa perjanjian yang telah berlaku mengikat bagi para pihak serta harus dilaksanakan dengan prinsip iktikad baik. Dengan demikian, prinsip dalam ketentuan Pasal 26 tersebut hanya berlaku terhadap pemenuhan kewajiban yang telah ada, yakni bagi perjanjian yang telah berlaku. ${ }^{20}$

Schwarzenberger dan E.D. Brown menyatakan iktikad baik sebagai salah satu dari prinsip-prinsip fundamental yang diakui di dalam hukum internasional guna mengatur pembentukan serta pelaksanaan kewajiban di dalam hukum internasional. ${ }^{21} \mathrm{Hal}$ ini sebagaimana yang dinyatakan oleh Mahkamah Internasional di dalam Nuclear Test Case sebagai berikut: ${ }^{22}$

"One of the basic principles governing the creation and performance of legal obligations, whatever their source, is the principle of good faith."

Prinsip iktikad baik secara universal diatur di dalam Pasal 2 ayat (2) Piagam PBB, yang berbunyi:

"All Members, in order to ensure to all of them the rights and benefits resulting from membership, shall fulfill in good faith the obligations assumed by them in accordance with the present Charter."

\footnotetext{
18 Anthony Aust, Modern Treaty Law And Practice, Cambridge: Cambridge University Press, 2000, hlm. 7.

19 F.A. Whisnu Situni, Identifikasi Dan Reformulasi Sumber-Sumber Hukum Internasional, Bandung: Mandar Maju, 1989, hlm. 35.

${ }^{20}$ Mark E. Villiger, Commentary on the 1969 Vienna Convention on the Law of Treaties, Leiden: Martinus Nijhoff Publishers, 2009, hlm. 365.

${ }^{21}$ Andrew D. Mitchell, "Good Faith in WTO Dispute Settlement", Melbourne Journal of International Law, Volume 7, 2006, hlm. 4.

${ }^{22}$ Nuclear Tests Case (Australia v. France), Merits, ICJ Rep 253, 1974.
} 
Ketentuan mengenai pelaksanaan prinsip iktikad baik diatur lebih lanjut di dalam Declaration on Principles of International Law concerning Friendly Relations and Co-operation among States in accordance with the Charter of the United Nations 1970 (Friendly Relations Declaration). Hal ini sebagaimana dikemukakan di dalam deklarasi tersebut, bahwa:

"The principle that States shall fulfil in good faith the obligations assumed by them in accordance with the Charter.

Every State has the duty to fulfil in good faith the obligations assumed by it in accordance with the Charter of the United Nations.

Every State has the duty to fulfil in good faith its obligations under the generally recognized principles and rules of international law.

Every State has the duty to fulfil in good faith its obligations under international agreements valid under the generally recognized principles and rules of international law."

Ketentuan di atas menunjukkan bahwa, prinsip untuk melaksanakan iktikad baik tidak hanya terbatas kepada perjanjian internasional tetapi juga diaplikasikan terhadap seluruh kewajiban internasional. ${ }^{23}$ Pada perkembangannya, prinsip iktikad baik muncul di dalam berbagai bentuk, termasuk di dalam negosiasi perjanjian internasional. Tidak terkecuali di dalam perjanjian pengembangan bersama sebagaimana yang dilaksanakan oleh Timor Leste dan Australia melalui CMATS.

Tahap negosiasi di dalam pembentukan perjanjian internasional memiliki peran penting bagi penyusunan ketentuan di dalam suatu perjanjian. Kewajiban tersebut tidak akan pernah berakhir dan hadir di seluruh bentuk hubungan antar negara. Hal ini sebagaimana diungkapkan oleh Hakim Padillo Nervo di dalam separate opinion North Sea Continental Shelf Case, bahwa: ${ }^{24}$

"The obligation to negotiate is an obligation of tracto continuo; it never

ends and is potentially present in all relations and dealing between states."

Dalam hal bernegosiasi untuk menetapkan pengaturan sementara mengenai wilayah yang bersengketa, baik Pasal 74 ayat (3) maupun Pasal 83 ayat (3) KHL telah menetapkan dua elemen, yakni kewajiban untuk mengadakan segala usaha untuk memutuskan pengaturan sementara serta larangan untuk menghambat pencapaian mengenai penetapan batas secara permanen. Kewajiban untuk melakukan negosiasi antar para pihak di dalam pengembangan bersama juga muncul di dalam kasus North Sea Contintental Shelf sebagai cikal bakal munculnya konsep pengembangan bersama. Hal ini sebagaimana yang dikemukakan oleh

\footnotetext{
${ }^{23}$ Anthony Aust, Op.cit., hlm. 9.

24 Tariq Hassan, "Good Faith in Treaty Formation", Virginia Journal of International Law, Volume 21, No. 3, 1981, hlm. 479.
} 
Mahkamah Internasional di dalam kasus tersebut, bahwa: ${ }^{25}$

"The parties are under an obligation to enter into negotiations with a view to arriving at an agreement, and not merely to go through a formal process of negotiation as a sort of prior condition for the automatic application of a certain method of delimitation in the absence of agreement; they are under an obligation so to conduct themselves that the negotiations are meaningful, which will not be the case when either of them insists upon its own position without contemplating any modification of it."

Berdasarkan putusan Mahkamah Internasional tersebut, suatu negosiasi harus dilakukan untuk mencapai suatu kesepakatan. Maka negosiasi tersebut harus dilaksanakan secara bermakna dan bukan hanya sebagai proses formal. Hal ini sebagaimana yang dikemukakan oleh Myron H. Nordquist, bahwa kewajiban untuk mengadakan segala usaha untuk menetapkan pengaturan sementara merupakan bentuk kewajiban untuk bernegosiasi. ${ }^{26}$

Iktikad baik sebagai salah satu prinsip hukum yang diakui di dalam hukum internasional merupakan pendukung dari pokok negosiasi mengenai penetapan batas maritim serta sumber daya alam di wilayah yang bersengketa. ${ }^{27}$ Di dalam KHL sendiri, ketentuan mengenai iktikad baik tersebut terdapat di dalam Pasal 300 yang mewajibkan para pihak untuk melaksanakan kewajiban yang diperintahkan oleh KHL dengan iktikad baik, serta melaksanakan hak, yurisdiksi dan kebebasan tanpa melanggar hak.

Pasal 300 KHL merefleksikan ketentuan Pasal 2 ayat (2) Piagam PBB sebagai ketentuan universal mengenai iktikad baik. Selain itu, Pasal 300 KHL juga mengandung aturan fundamental pacta sunt servanda di Pasal 26 Konvensi Wina yang berhubungan dengan perjanjian internasional. ${ }^{28}$ Pacta sunt servanda, yang merupakan kewajiban di dalam perjanjian internasional serta hukum kebiasaan internasional, ${ }^{29}$ mewajibkan para pihak untuk melaksanakan ketentuan di dalam perjanjian yang telah berlaku dan mengikat bagi mereka dengan iktikad baik.

Pasal 74 ayat (3) dan Pasal 83 ayat (3) KHL merupakan suatu bentuk kewajiban yang mengamanatkan pembentukan suatu pengaturan sementara di dalam pengelolaan sumber daya alam bagi negara-negara yang pantainya berhadapan, namun penetapan batas maritimnya belum disepakati. Dengan demikian, kewajiban bagi negara-negara anggota KHL untuk membentuk suatu

\footnotetext{
${ }^{25}$ North Sea Continental Shelf Cases (Denmark v. Netherlands), Judgment, ICJ Reports, 1969.

${ }^{26}$ Myron H. Nordquist, Volume III, Loc. cit.

27 Donald K. Anton, "Arbitrating the Treaty on Certain Maritime Arrangements in the Timor Sea: The Latest Round between Timor-Leste and Australia", ANU College of Law Research Paper, No. 13-20, 2013.

${ }^{28}$ Myron H. Nordquist, United Nations Convention on the Law of the Sea 1982 A Commentary, Volume V, Dordrecht: Martinus Nijhoff Publishers, 1989, hlm. 152.

${ }^{29}$ Andrew D. Mitchell, Loc. cit.
} 
pengembangan bersama harus dilaksanakan dengan prinsip iktikad baik sebagaimana diatur oleh Pasal $300 \mathrm{KHL}$, termasuk di dalam tahap negosiasi.

Sebagaimana yang dikemukakan oleh British Institute of International and Comparative Law, bahwa muatan kewajiban yang diatur di dalam ketentuan Pasal 74 ayat (3) dan Pasal 83 ayat (3) tersebut ialah untuk bernegosiasi secara iktikad baik untuk mencapai suatu persetujuan mengenai pengembangan di wilayah yang penetapan batasnya yang tertunda. ${ }^{30} \mathrm{Hal}$ ini dikonfirmasi oleh dewan arbitrase PCA di dalam kasus Guyana v. Suriname mengenai maksud dari "segala usaha" atau "every effort" di dalam Pasal 74 ayat (3) dan 83 ayat (3) memberikan maksud sebagai berikut: ${ }^{31}$

"...the language in which the obligation is framed imposes on the Parties a duty to negotiate in good faith."

Dengan demikian dapat dinyatakan bahwa salah satu kewajiban bagi negaranegara anggota KHL dalam membentuk suatu pengembangan bersama adalah untuk bernegosiasi dengan prinsip iktikad baik.

\section{Penyadapan oleh ASIS sebagai Bentuk Kecurangan di dalam Pembentukan Pengaturan Sementara Mengenai Pengembangan Bersama CMATS}

Timor Leste mengajukan pengajuan penyelesaian sengketa melalui jalur arbitrase sebagai pembatalan CMATS atas dasar tidak dilaksanakannya prinsip iktikad baik di dalam negosiasi CMATS oleh Australia dengan dilakukannya tindak penyadapan. ${ }^{32}$ Berkaitan dengan pembatalan atau ketidakabsahan terhadap CMATS, maka tindak penyadapan tersebut harus dapat dibuktikan sebagai salah satu dasar pembatalan sebagaimana diatur dalam Konvensi Wina. Ketentuan mengenai pembatalan perjanjian internasional terdapat pada Bab $\mathrm{V}$ dan dasar-dasar pembatalan perjanjian internasional diatur pada Pasal 46 - Pasal 53 Kovensi Wina. Salah satu dasar pembatalan tersebut ialah kecurangan yang dilakukan oleh negara mitra berunding. ${ }^{33}$

Berdasarkan Pasal 49 Konvensi Wina, bahwa suatu negara dapat menyatakan ketidakabsahan atau batalnya suatu perjanjian yang telah disetujui apabila terdapat kecurangan dari negara mitra berunding. Maka agar suatu perjanjian dapat

\footnotetext{
${ }^{30}$ Hazel Fox (et.al.), Op.cit., hlm. 38.

31 Arbitral Tribunal Constituted Pursuant to Article 287, And In Accordance With Annex VII, of the United Nations Convention on the Law of the Sea (Guyana v. Suriname), Award of the Arbitral Tribunal, PCA, 2007, hlm. 153, para. 461.

32 Australian Minister for Foreign Affairs, "Arbitration Under the Timor Sea Treaty", 2013, http://foreignminister. gov.au/releases/2013/bc_mr_130503.html, diakses 25 Agustus 2014.

33 Paul Reuteur, Introduction to the Law of Treaties, London: Kegan Paul International, 1995, hlm. 173. Lihat juga Kate Michell dan Dapo Akande, "Espionage \& Good Faith in Treaty Negotiations: East Timor v. Australia", 2014, http://www.ejiltalk.org/espionage-fraud-good-faith-in-treaty-negotiations-east-timor-v-australia-in-thepermanent-court-of-arbitration/, diakses 25 September 2014.
} 
dibatalkan harus terdapat unsur 'melakukan penipuan' atau fraudulent conduct di dalam pembuatan perjanjian. Komisi Hukum Internasional atau International Law Commission (ILC) memberikan kriteria bagi fraudulent conduct, antara lain sebagai pernyataan palsu yang disengaja (false statement), kesalahan tafsir (misrepresentations), maupun tindakan yang tidak jujur atau tipu daya (deceitful proceedings) lainnya yang menyebabkan negara mitra memberikan persetujuan terhadap perjanjian, namun sesungguhnya persetujuan tersebut tidak akan diberikan apabila tindakan kecurangan tersebut telah diketahui sebelumnya. ${ }^{34}$ Selain itu Fitzmaurice menyatakan bahwa kecurangan di dalam pembentukan perjanjian internasional dapat berupa:

"[fraud must have] induced, or contributed to inducing, the other party to conclude or participate in the treaty, in such a way that that party would not otherwise have done so."35

Salah satu praktik yang berkaitan dengan kecurangan di dalam perjanjian internasional merupakan The Munich Agreement 1938 yang diadakan oleh Pemerintah Jerman saat masih dikuasai oleh Nazi. Perjanjian tersebut pada awalnya ditujukan untuk mempersatukan kaum minoritas Jerman di Sudetenland, sebuah kota di Cekoslovakia, dengan cara menggabungkan kota tersebut dengan wilayah Jerman melalui aneksasi. Pemerintah Nazi melalui pemimpinnya, yakni Hitler, mengajak Britania Raya, Italia, dan Perancis untuk menandatangani perjanjian tersebut tanpa terlebih dahulu berkonsultasi dengan Cekoslovakia. Namun demikian, ternyata Pemerintah Nazi tidak pernah bermaksud untuk memenuhi ketentuan inti perjanjian tersebut. Pemerintah Nazi sejak awal berniat untuk melakukan aneksasi sepenuhnya terhadap seluruh wilayah Cekoslovakia. ${ }^{36}$ Perjanjian tersebut kemudian dinyatakan batal dan tidak sah ab initio. ${ }^{37}$ Berdasarkan contoh praktik tersebut, karakteristik kecurangan ditentukan berdasarkan niat dari negara perunding.

Penyadapan adalah cara mendapatkan bahan keterangan dengan menyadap sistem komunikasi pihak sasaran yang dilakukan secara rahasia, tanpa diketahui oleh sasaran atau pihak-pihak lain. ${ }^{38}$ Craig Forceses membagi kegiatan intelijen tersebut ke dalam tiga pembagian geografi, yakni: domestik (territorial); non-

\footnotetext{
${ }^{34}$ Anthony Aust, Op.cit., hlm. 255. Lihat juga International Law Commission, "Report of the International Law Commission Covering Its 16th Session, 727th Meeting, 20 May 1964", Yearbook of the International Law Commission, 1964, hlm. 245.

35 Oliver Dorr (eds.), Vienna Convention on the Law of Treaties A Commentary, Heidelberg: Springer, 2012, hlm. 837.

${ }^{36}$ The Editors of Encyclopedia Britannica, "Munich Agreement", 2013, http://www.britannica.com/EBchecked /topic/397522/Munich-Agreement, diakses 25 September 2014. Lihat juga International Law Commission, "Summary Record of the Fifteen Session, 6 may-12 july 1963", Yearbook of the International Law Commission, Vol. I, 1963, hlm. 31.

37 Oliver Dorr (eds.), Loc.cit.

${ }^{38}$ Y. Wahyu Saronto, Intelijen Teori, Aplikasi dan Modernisasi, Jakarta: PT Ekalaya Saputra, 2004, hlm. 51.
} 
domestik (extraterritorial); dan transnasional sebagaimana ditunjukkan oleh tabel berikut ini: ${ }^{39}$

\section{Tabel 1.}

\section{Geography of Spying}

\begin{tabular}{|c|c|c|c|}
\hline & Territorial & Extraterritorial & Transnational \\
\hline $\begin{array}{c}\text { Human } \\
\text { intelligence }\end{array}$ & $\begin{array}{l}\text { Collection of } \\
\text { information by a } \\
\text { state agent from } \\
\text { people and their } \\
\text { associated } \\
\text { documents and } \\
\text { media sources that } \\
\text { takes place within } \\
\text { the state. }\end{array}$ & $\begin{array}{l}\text { Collection of } \\
\text { information by a } \\
\text { state agent from } \\
\text { people and their } \\
\text { associated } \\
\text { documents and } \\
\text { media sources that } \\
\text { takes place on the } \\
\text { territory of another } \\
\text { state. }\end{array}$ & $\begin{array}{l}\text { Collection of } \\
\text { information by a } \\
\text { state agent from } \\
\text { people and their } \\
\text { associated documents } \\
\text { and media sources in } \\
\text { which the source (but } \\
\text { not the agent) is } \\
\text { located on the territory } \\
\text { of another state. }\end{array}$ \\
\hline $\begin{array}{c}\text { Electronic } \\
\text { surveillance }\end{array}$ & $\begin{array}{l}\text { Interception of } \\
\text { communications or } \\
\text { actions passed by } \\
\text { radio, wire, or } \\
\text { other } \\
\text { electromagnetic, } \\
\text { photo-electronic } \\
\text { and/or photo-optical } \\
\text { means and of } \\
\text { electromagnetic } \\
\text { radiations in which } \\
\text { both the } \\
\text { communication } \\
\text { and the interception } \\
\text { takes place within } \\
\text { the state. }\end{array}$ & $\begin{array}{l}\text { Interception of } \\
\text { communications or } \\
\text { actions passed by } \\
\text { radio, wire, or } \\
\text { other } \\
\text { electromagnetic, } \\
\text { photo-electronic } \\
\text { and/or photo-optical } \\
\text { means and of } \\
\text { electromagnetic } \\
\text { radiations in which } \\
\text { both the } \\
\text { communication } \\
\text { and the interception } \\
\text { take place on the } \\
\text { territory of another } \\
\text { state. }\end{array}$ & $\begin{array}{l}\text { Interception of } \\
\text { communications or } \\
\text { actions passed by } \\
\text { radio, wire, or other } \\
\text { electromagnetic, } \\
\text { photo-electronic and/or } \\
\text { photo-optical } \\
\text { means and of } \\
\text { electromagnetic } \\
\text { radiations in which } \\
\text { the communication } \\
\text { (but not the } \\
\text { interception) takes } \\
\text { place on the territory of } \\
\text { another the state. }\end{array}$ \\
\hline
\end{tabular}

Kegiatan penyadapan yang dilakukan oleh ASIS termasuk ke dalam kategori kegiatan intelijen ekstra territorial karena dilangsungkan oleh agen intelijen suatu negara di wilayah negara lain. Penyadapan oleh ASIS di dalam negosiasi CMATS yang dilaksanakan dengan cara menyusup secara tidak sah ke wilayah teritorial Timor Leste, serta dengan menyamar sebagai kontraktor bagi program AusAID, merupakan bentuk tindakan yang tidak jujur atau tipu daya di dalam bernegosiasi. Hal tersebut menunjukkan bahwa Australia telah menunjukkan niat yang tidak baik

${ }^{39}$ Craig Forcese, "Spies without Borders: International Law and Intelligence Collection", Journal of National Security Law and Policy, Volume 5, No. 179, 2011, hlm. 183. 
di dalam membentuk CMATS dengan berusaha memperoleh informasi mengenai negosiasi internal pemerintah Timor Leste melalui cara yang ilegal yaitu melalui tindak penyadapan yang dilakukan oleh ASIS di wilayah teritorial, dalam hal ini kantor pemerintahan Timor Leste, merupakan tindakan yang mengancam integritas wilayah atau kemerdekaan politik suatu negara berdasarkan ketentuan Pasal 2 ayat (4) Piagam PBB. Hal ini sebagaimana didukung oleh pernyataan dari Ingrid Delupis, bahwa:

"Espionage appears to be illegal under international law in time of peace if it involves the presence of agents sent clandestinely by a foreign power into the territory of another state." 40

Selain itu, menurut Quincy Wright, penyadapan sebagai bentuk spionase yang dilakukan di masa damai dengan memasuki wilayah teritorial negara lain merupakan pelanggaran terhadap hukum nasional negara tersebut juga terhadap kewajiban hukum internasional untuk menghargai integritas teritorial dan kemerdekaan politik negara lain. ${ }^{41}$ Dalam hal ini, Timor Leste mengatur kegiatan intelijen di wilayah nasionalnya melalui Law 9/2008 on the Intelligence System of the Democratic Republic of Timor Leste. Pasal 19 ayat (1) dan ayat (2) undangundang tersebut menyatakan, bahwa:

(1) State secrecy shall apply to data and intelligence the dissemination of which is susceptible of causing damage to the unity and integrity of the State, to the defence of the democratic institutions provided for in the Constitution, to the free exercise of their respective functions by the organs of sovereignty, to the internal security, to national independence, and to preparations for military defence.

(2) Registrations, documents, files and archives of the intelligence services relating to matters referred to in the preceding paragraph shall be covered by the State secrecy and shall not be the object of requisition or examination by any entity alien to the services, except the members of the Monitoring Council in exercise of functions.

Berdasarkan ketentuan pasal tersebut, hasil diskusi pemerintah Timor Leste dianggap sebagai rahasia negara sebagai bentuk pelaksanaan fungsi organ-organ kedaulatan Timor Leste. Penyadapan oleh ASIS terhadapnya merupakan bentuk pelanggaran terhadap ketentuan Pasal 19 ayat (2) yang melarang hasil negosiasi sebagai rahasia negara untuk menjadi objek pengambilalihan dan pemeriksaan oleh entitas asing.

\footnotetext{
${ }^{40}$ A. John Radsan, "The Unresolved Equitation Espionage and International Law", Michigan Journal of International Law, Volume 28, No. 597, 2007, hlm. 605.

${ }^{41}$ Quincy Wright, "Espionage and the Doctrine of Non-Intervention in Internal Affairs", dalam buku Essays on Espionage and International Law yang disusun oleh Roland J. Stanger (ed), Ohio: Ohio State University Press, 1982, hlm. 12.
} 
Dengan demikian, tindakan penyadapan ini merupakan bentuk kecurangan atau fraudulent conduct oleh Australia di dalam pembentukan CMATS karena tindakan tersebut dilakukan dengan tipu daya serta bertentangan dengan hukum internasional dan hukum nasional Timor Leste sendiri. Maka dari itu, Timor Leste dapat memohonkan pembatalan bagi perjanjian tersebut.

\section{Penyadapan sebagai Bentuk Kecurangan di dalam Pembentukan CMATS Merupakan Pelanggaran terhadap Prinsip Iktikad Baik yang Mengakibatkan Pembatalan}

Ketentuan Pasal 74 ayat (3) dan Pasal 83 ayat (3) KHL mengandung elemen kewajiban untuk menyelenggarakan usaha-usaha pembentukan pengaturan sementara. Kewajiban di dalamnya termasuk untuk bernegosiasi dengan prinsip iktikad baik dalam rangka membentuk pengaturan sementara melalui pengembangan bersama. Selain itu, KHL juga menetapkan pelaksanaan kewajiban di dalamnya agar dilaksanakan dengan prinsip iktikad baik sebagaimana diatur oleh Pasal $300 \mathrm{KHL}$. Tentu saja, kewajiban yang diakomodasi oleh Pasal 300 tersebut termasuk mengenai pembentukan pengaturan sementara mengenai pengembangan bersama.

Penyadapan oleh ASIS terhadap negosiasi CMATS merupakan suatu bentuk kecurangan agar perjanjian dapat dibatalkan. Sebagaimana yang terjadi di dalam praktik The Munich Agreement 1938, bahwa karakteristik kecurangan ditentukan berdasarkan niat dari negara perunding. Berdasarkan niat dari Pemerintah Nazi yang sejak awal akan melanggar kesepakatan dalam perjanjian tersebut dengan menganeksasi Cekoslovakia, maka hal tersebut menunjukan iktikad buruk atau bad faith dari Pemerintah Nazi. ${ }^{42}$ Iktikad baik merupakan unsur penentu, yang merupakan pendukung dari pembentukan kewajiban-kewajiban positif di dalam suatu perjanjian. ${ }^{43}$ Sehingga dapat dinyatakan bahwa kecurangan di dalam perjanjian internasional bertalian dengan pelanggaran terhadap kewajiban untuk melaksanakan perjanjian dengan iktikad baik.

Tindakan penyadapan tersebut merupakan kontribusi terhadap pembentukan CMATS. Informasi yang diperoleh melalui penyadapan kemudian dipergunakan untuk merumuskan ketentuan-ketentuan di dalam CMATS yang dianggap dapat menguntungkan pihak Australia. Selain itu, operasi penyadapan yang dilakukan pada masa negosiasi CMATS melalui dalih bantuan AusAID bagi Timor Leste merupakan suatu bentuk tipu daya. Selain itu, dilakukannya penyadapan di dalam negosiasi CMATS mengakibatkan Australia memperoleh keuntungan informasi mengenai negosiasi internal Timor Leste. Keadaan tersebut menyebabkan terdapat

\footnotetext{
42 The Editors of Encyclopedia Britannica, Loc.cit.

${ }^{43}$ Mark E. Villiger, Op.cit., hlm. 617.
} 
perbedaan kekuatan negosiasi di antara Timor Leste dan Australia. Akses informasi mengenai negosiasi suatu perjanjian internasional yang diperoleh melalui penyadapan dapat membatasi kemampuan para pihak untuk bernegosiasi secara bebas dan adil. ${ }^{44}$ Oleh karena itu, tindakan penyadapan ini merupakan bentuk kecurangan atau fraudulent conduct oleh Australia di dalam pembentukan CMATS. Dengan demikian, hal tersebut tentunya bertentangan dengan prinsip iktikad baik. ${ }^{45}$

Kecurangan yang dilakukan dengan tindak penyadapan oleh Australia terhadap negosiasi CMATS dianggap telah melanggar kewajiban untuk bernegosiasi dengan prinsip iktikad baik di dalam proses pembentukan pengembangan bersama, sebagaimana yang dimuat oleh Pasal 74 ayat (3) dan Pasal 83 ayat (3) KHL, serta yang ditegaskan lebih lanjut oleh Pasal 300 KHL. Lebih lanjut lagi ketentuan Pasal 9 PLT mewajibkan kedua pihak untuk mencapai suatu pengaturan dengan prinsip iktikad baik yang akan menghasilkan solusi agar endapan dapat dikelola secara efektif serta pembagian hasilnya merata. Pasal tersebut berbunyi sebagai berikut:

"East Timor and Australia shall work expeditiously and in good faith to reach agreement on the manner in which the deposit will be most effectively exploited and on the equitable sharing of the benefits arising from such exploitation."

Dengan mendasarkan kepada penafsiran berdasarkan Pasal 31 Konvensi Wina dengan pendekatan kepada naskah perjanjian, kalimat "to reach agreement" di dalam Pasal 9 PLT merefleksikan usaha kedua pihak untuk dapat mencapai suatu pengaturan. Usaha tersebut diimplementasikan melalui tindakan negosiasi. Selain berdasarkan naskah perjanjian, kalimat tersebut juga merefleksikan kewajiban negosiasi berdasarkan maksud para pihak sebagaimana yang terdapat di dalam Explanatory Memorandum Petroleum (Timor Sea Treaty) Bill 2003. ${ }^{46}$

Australia dan Timor Leste telah meratifikasi PLT ke dalam hukum nasional masing-masing negara. Timor Leste telah meratifikasi PLT melalui National Parliament Resolution No. 2/2003. Sedangkan Australia meratifikasi PLT melalui Petroleum Bill 2003. Sehingga ketentuan di dalam PLT telah berlaku dan mengikat para pihak, serta wajib dilaksanakan dengan prinsip iktikad baik.

Penyadapan oleh Australia terhadap negosiasi pemerintah Timor Leste dalam rangka pembentukan CMATS sebagai aplikasi dari ketentuan unitisasi berdasarkan Pasal 9 PLT merupakan suatu bentuk kecurangan. Penyadapan tersebut merupakan bentuk pelanggaran terhadap kewajiban untuk bernegosiasi dengan prinsip iktikad

\footnotetext{
${ }^{44}$ Kate Michell dan Dapo Akande, Loc.cit.

${ }^{45}$ Donald K. Anton, Loc. cit.

${ }^{46}$ House of Representatives, "Explanatory Memoranda Petroleum (Timor Sea Treaty) Bill”, 2010, http://parlinfo.aph.gov.au/parllnfo/search/display/display.w3p;query=Id\%3A\%22legislation\%2Fems\%2Fr1755 _ems_8b015020-b07d-4628-8ff1-6dc428a39d6c\%22, diakses 18 September 2014.
} 
baik pada tahap pembentukan atau pembuatan CMATS sebagai perjanjian internasional mengenai pengembangan bersama sebagaimana yang diamanatkan oleh Pasal 74 ayat (3) dan Pasal 83 ayat (3) KHL yang didukung oleh ketentuan Pasal $300 \mathrm{KHL}$. Meskipun CMATS pada tahap negosiasi masih belum mengikat bagi Australia maupun Timor Leste, namun ketentuan pada perjanjian yang mendahului CMATS, yakni PLT, telah mengikat dan mewajibkan kedua negara untuk di kemudian hari dapat mencapai suatu pengaturan yang baru dengan prinsip iktikad baik. Bentuk usaha untuk mencapai pengaturan tersebut ialah dengan negosiasi. Sebagai perjanjian yang telah mengikat, maka timbul kewajiban berdasarkan prinsip pacta sunt servanda di Pasal 26 Konvensi Wina untuk Timor Leste dan Australia agar melaksanakan PLT dengan prinsip iktikad baik, termasuk dalam hal mengadakan usaha untuk mencapai pengembangan bersama melalui negosiasi. Maka dari itu, tindakan penyadapan sebagai bentuk kecurangan tersebut telah melanggar kewajiban Australia untuk bernegosiasi dengan prinsip iktikad baik, baik berdasarkan ketentuan Pasal 9 TST maupun ketentuan Pasal 26 Konvensi Wina.

Sebagaimana yang telah dipaparkan sebelumnya, karena penyadapan oleh Australia sebagai pelanggaran prinsip iktikad baik termasuk sebagai bentuk kecurangan di dalam pembentukan CMATS maka berdasarkan ketentuan Pasal 49 Konvensi Wina, CMATS dapat dibatalkan. Karena CMATS merupakan perjanjian bilateral, maka ketidakabsahan tersebut tidak hanya mengenai pembatalan kesepakatan mengikatkan diri terhadap CMATS dari Timor Leste saja, tetapi ketidakabsahan tersebut juga berkaitan dengan batalnya CMATS secara keseluruhan. ${ }^{47}$ Dengan demikian, akibat hukum dari pelanggaran prinsip iktikad baik di dalam negosiasi ialah batalnya CMATS. Hal ini sebagaimana diatur di dalam Pasal 69 ayat (1) Konvensi Wina, bahwa:

"A treaty the invalidity of which is established under the present Convention is void. The provisions of a void treaty have no legal force."

Berdasarkan ketentuan di atas, maka perjanjian bilateral akan batal $a b$ initio atau sejak awal sekaligus ketentuan-ketentuan di dalamnya tidak akan memiliki kekuatan hukum. Hal ini sebagaimana yang diungkapkan oleh Paul Reuteur yang menyatakan bahwa suatu penyelesaian sengketa mengenai perjanjian internasional akan memberikan dampak bagi perjanjian tersebut bahkan semenjak pertama kali alasan untuk tidak menerapkan perjanjian tersebut muncul. Beliau juga menyatakan apabila perjanjian dinyatakan batal demi hukum, maka perjanjian tersebut dianggap tidak dapat memberikan akibat apapun semenjak munculnya dasar pembatalan tersebut. ${ }^{48}$

\footnotetext{
47 Ian Sinclair, The Vienna Convention on the Law of Treaties Second Edition, Manchester: Manchester University Press, 1984, hlm. 160.

48 Paul Reuteur, Op.cit., hlm. 171.
} 
Dengan dibatalkannya CMATS, maka perjanjian tersebut dipandang sama sekali tidak pernah ada serta ketentuan-ketentuan di dalamnya tidak lagi memiliki kekuatan hukum. ${ }^{49}$ Maka apabila CMATS menjadi batal, segala kegiatan pengelolaan sumber daya alam di ladang Greater Sunrise yang didasarkan kepada ketentuan di dalam CMATS tidak lagi memiliki kepastian hukum. Dengan demikian, pengelolaan ladang Greater Sunrise beserta pembagian pendapatannya kembali diatur oleh ketentuan di dalam IUA.

\section{E. Penutup}

Tindakan penyadapan yang dilakukan oleh ASIS merupakan bentuk pelanggaran terhadap integritas wilayah serta kedaulatan Timor Leste, yang bertentangan dengan prinsip untuk tidak melanggar integritas wilayah dan kemerdekaan politik sebagaimana diatur di dalam Pasal 2 ayat (4) Piagam PBB. Selain itu, tindak penyadapan juga dianggap telah melanggar ketentuan di dalam hukum nasional Timor Leste itu sendiri, yakni Pasal 19 Law-9/2008 on the Intelligence System of the Democratic Republic of Timor Leste yang melindungi hasil negosiasi internal pemerintah sebagai rahasia negara dan mencegah informasi tersebut untuk menjadi objek pemeriksaan entitas asing. Maka dapat disimpulkan, bahwa usaha Australia untuk memperoleh informasi mengenai negosiasi internal pemerintah Timor Leste mengenai CMATS bertentangan dengan hukum internasional. Sehingga tindak penyadapan terhadap negosiasi tersebut termasuk ke dalam kategori kecurangan atau fraudulent conduct.

Tindakan penyadapan oleh Australia sebagai fraudulent conduct merupakan suatu pelanggaran terhadap kewajiban untuk melaksanakan prinsip iktikad baik di dalam negosiasi pengembangan bersama sebagaimana diatur oleh Pasal 74 ayat (3) dan Pasal 83 ayat (3) KHL. Kewajiban tersebut juga tercantum di dalam Pasal 300 $\mathrm{KHL}$ yang berkaitan dengan prinsip pacta sunt servanda di dalam Pasal 26 Konvensi Wina. Karena tindak penyadapan yang dilakukan oleh ASIS tersebut merupakan bentuk kecurangan, maka dari itu apabila tindak penyadapan tersebut terbukti, Dewan Arbitrase CMATS dapat mengabulkan permohonan Timor Leste agar perjanjian tersebut dibatalkan atas dasar ketentuan Pasal 49 Konvensi Wina mengenai kecurangan. Sehingga batalnya CMATS mengakibatkan segala ketentuan di dalam CMATS tidak lagi memiliki kekuatan hukum karena perjanjian tersebut dipandang tidak pernah ada.

Selama ini, proses negosiasi yang dilakukan oleh Timor Leste dengan Australia selama 12 tahun sering mengalami kendala karena kedua negara bersikukuh untuk mengedepankan kepentingan nasional masing-masing negara tanpa berkompromi

\footnotetext{
49 I Wayan Parthiana, Hukum Perjanjian Internasional, Bagian 2, Bandung: Mandar Maju, 2002, hlm. 450.
} 
terhadap kebutuhan negara mitra. Seringkali kesepakatan yang dicapai tidak secara lapang dada diterima oleh salah satu pihak, karena kesepakatan tersebut dianggap tidak menguntungkan. Selain itu, terjadi pula kesepakatan yang dicapai lantaran adanya tekanan dari pihak lain. Oleh karena itu, penyelesaian sengketa CMATS serta pembentukan perjanjian mengenai penetapan batas maritim yang akan dibuat oleh Australia dan Timor Leste di kemudian hari agar dilaksanakan dengan menggunakan proses yang menghadirkan pihak ketiga. Dengan begitu, maka diharapkan kepentingan masing-masing negara dapat diakomodasi dan hak-hak kedua negara dapat diperoleh secara adil dengan mendasarkan kepada KHL.

Pengelolaan sumber daya alam di antara Australia dan Timor Leste selama ini masih diatur sebatas pengaturan sementara saja, serta di antara kedua negara masih belum terdapat kesepakatan penetapan batas maritim yang menjadikan kegiatan eksplorasi dan eksploitasi sumber daya alam di wilayah JDPA maupun ladang Greater Sunrise kekurangan kepastian hukum. Oleh karena itu, kedua negara harus mulai mendiskusikan penetapan batas maritim yang sah secara hukum internasional dengan mendasarkan kepada ketentuan KHL mengenai penetapan lebar landas kontinen dan ZEE kedua wilayah. Dengan ditetapkannya batas maritim di antara kedua negara, maka akan terdapat kepastian hukum mengenai yurisdiksi, kedaulatan, serta hak berdaulat dari masing-masing negara terhadap ZEE dan landas kontinennya. Adanya kepastian hukum tersebut juga dapat membuka kesempatan bagi perusahaan-perusahaan yang bergerak di bidang minyak dan gas untuk melakukan kerja sama dengan Australia maupun Timor Leste dalam mengelola sumber daya alam di wilayah kedua negara tanpa harus khawatir akan ketidakpastian hukum bagi proyek-proyek mereka.

Selain bagi hubungan kedua negara, penetapan batas maritim yang sah juga dapat memiliki pengaruh bagi penetapan batas maritim bagi Indonesia. Hal tersebut karena selama ini penetapan batas maritim antara Australia dan Indonesia dilakukan berdasarkan pengaturan sementara sebagaimana yang dilakukan antara Australia dan Timor Leste. Dengan ditetapkannya penetapan batas maritim permanen, maka Indonesia juga dapat menyesuaikan penetapan batas maritim permanen miliknya sehingga terdapat kepastian hukum bagi pengelolaan sumber daya alam antara Indonesia dan Australia. 


\section{Daftar Pustaka}

\section{Buku}

Aust, Anthony, Modern Treaty Law And Practice, Cambridge University Press, Cambridge, 2000.

Dorr, Oliver (eds.), Vienna Convention on the Law of Treaties A Commentary, Springer, Heidelberg, 2012.

F.A. Whisnu Situni, Identifikasi Dan Reformulasi Sumber-Sumber Hukum Internasional, Mandar Maju, Bandung, 1989.

Fox, Hazel (et.al.), Joint Development of Offshore Oil and Gas: A Model Agreement for States for Joint Development with Explanatory Commentary, British Institute of International and Comparative Law, London,1989.

I Wayan Parthiana, Hukum Perjanjian Internasional, Bagian 2, Mandar Maju, Bandung, 2002.

Nordquist, Myron H., United Nations Convention on the Law of the Sea 1982 A Commentary, Volume III, Martinus Nijhoff Publishers, Dordrecht, 1989.

United Nations Convention on the Law of the Sea 1982 A Commentary, Volume V, Martinus Nijhoff Publishers, Dordrecht, 1989.

Pranoto Iskandar, Hukum HAM Internasional Sebuah Pengantar Konstektual, IMR Press, Cianjur, 2013.

Reuteur, Paul, Introduction to the Law of Treaties, Kegan Paul International, London, 1995.

Sinclair, Ian, The Vienna Convention on the Law of Treaties, Second Edition, Manchester University Press, Manchester, 1984.

Stanger, Roland J. (ed), Essays on Espionage and International Law, Ohio State University Press, Ohio, 1982.

Y. Wahyu Saronto, Intelijen Teori, Aplikasi dan Modernisasi, PT Ekalaya Saputra, Jakarta, 2004.

\section{Dokumen Lain}

Anton, Donald K., "Arbitrating the Treaty on Certain Maritime Arrangements in the Timor Sea : The Latest Round between Timor-Leste and Australia", ANU College of Law Research Paper, No.13-20, 2013.

Arbitral Tribunal Constituted Pursuant to Article 287, And In Accordance With Annex VII, of the United Nations Convention on the Law of the Sea (Guyana v. Suriname), Award of the Arbitral Tribunal, Permanent Court of Arbitration, 2007. 
Australian Minister for Foreign Affairs, "Arbitration Under the Timor Sea Treaty", 2013, http://foreignminister.gov.au/releases/2013/bc_mr_130503.html, diakses 25 Agustus 2014.

Department of Foreign Affairs and Trade, "Entry into Force of Greater Sunrise Treaties with East Timor," Alexander Downer, Minister of Foreign Affairs, Australia, media release, 2007, www.foreignminister.gov.au/releases/2007, diakses 13 Juni 2014.

Forcese, Craig, "Spies Without Borders: International Law and Intelligence Collection", Journal of National Security Law and Policy, Volume 5, No. 179, 2011.

Hassan, Tariq, "Good Faith in Treaty Formation", Virginia Journal of International Law, Volume 21 No. 3, 1981.

House of Representatives, "Explanatory Memoranda Petroleum (Timor Sea Treaty) Bill”, 2010, http://parlinfo.aph.gov.au/parlInfo/search/display/display.w3p; query=Id\%3A\%22legislation\%2Fems\%2Fr1755_ems_8b015020-b07d-46288ff1-6dc428a39d6c\%22, diakses 18 September 2014.

International Law Commission, "Report of the International Law Commission Covering its 16th Session, 727th Meeting, 20 May 1964", Yearbook of the International Law Commission, 1964.

Llyod, Peter, "Brandis Orders ASIO Raids Related To East Timor Spying Case", 2013, http://www.abc.net.au/am/content/2013/s3904457.htm, diakses 27 Februari 2014.

Mitchell, Andrew D., "Good Faith in WTO Dispute Settlement", Melbourne Journal of International Law, Volume 7, 2006.

Neves, Guteriano (et.al.), "LNG Sunrise di Timor-Leste: Impian, Kenyataan dan Tantangan", Laporan La'o Hamutuk Institut Pemantau dan Rekonstruksi Timor Leste, 2008.

North Sea Continental Shelf Cases (Denmark v. Netherlands), Judgement, International Court of Justice (ICJ) Reports, 1969.

Nuclear Tests Case (Australia v France), Merits, ICJ Rep 253, 1974.

Parlemen Australia, "Australia-East Timor Certain Maritime Arrangements Treaty", Report 85: Treaties Tabled On 6, 7\& 27 February 2007, 2007.

Radsan, A. John, "The Unresolved Equitation Espionage and International Law", Michigan Journal of International Law, Volume 28, No. 597, 2007. 
Simpson, Susan, "A Timeline of Events Leading up to Timor-Leste's ICJ Claims Againts Australia", 2014, http://viewfromll2.com/2014/01/25/a-timeline-of-eventsleading-up-to-timor-lestes-icj-claim-against-australia/, diakses 27 Februari 2014.

The Editors of Encyclopedia Britannica, "Munich Agreement", 2013, http://www.britannica.com/EBchecked/topic/397522/Munich-Agreement, diakses 25 September 2014.

Timor Leste v. Australia, Pending Cases, PCA, 23 April 2013, http://www.pcacpa.org/showpage.asp?pag_id=1403, diakses 27 Februari 2014.

\section{Dokumen Hukum}

Treaty Between Australia and the Democratic Republic of Timor-Leste on Certain Maritime Arrangements in the Timor Sea, 12 Januari 2006, ATS 12. 